Interactive comment on "Development of a global 30-m impervious surface map using multi-source and multi-temporal remote sensing datasets with the Google Earth Engine platform" by Xiao Zhang

\title{
et al.
}

Xiao Zhang et al.

liuly@radi.ac.cn

Received and published: 2 May 2020

We thank the referee for reviewing our manuscript. Please find attached a pointbypoint reply to each of the comments raised by the referee with legible text and figures organized along the text.

Please also note the supplement to this comment: https://www.earth-syst-sci-data-discuss.net/essd-2019-200/essd-2019-200-AC1- 
Interactive comment on Earth Syst. Sci. Data Discuss., https://doi.org/10.5194/essd-2019-200, 2020.

\section{ESSDD}

Interactive comment 